\title{
Investigation of the Effect of 6-week Yoga Exercises on Balance, Flexibility, and Strength in Soccer Players
}

\author{
Alper Kartal", Esin Ergin \\ Faculty of Sport Science, Aydın Adnan Menderes University, 09100, Aydın, Turkey
}

Received April 3, 2020; Revised May 5, 2020; Accepted May 20, 2020

Copyright $(2020$ by authors, all rights reserved. Authors agree that this article remains permanently open access under the terms of the Creative Commons Attribution License 4.0 International License

\begin{abstract}
The aim of this study was to investigate the effect of 6-week yoga exercises on balance, flexibility, strength, and body fat percentage in soccer players. The sample group of the study consisted of 26 soccer players in a team, competing in the Turkish 1st League, with a mean height of $180.81 \pm 6.87$ centimeters $(\mathrm{cm})$, mean body weight of $75.77 \pm 9.08$ kilograms $(\mathrm{kg})$, and a body mass index (BMI) of $23.10 \pm 1.62$. Basic-level strength yoga exercise techniques were applied to soccer players for 6 weeks, 4 times a week each for 30 minutes before morning soccer training. The participants' balance, flexibility, and strength measurements were carried out twice, before and after 6-week yoga exercises. An Easytech dynamic balance system was used for balance measurements, a Takei-branded handgrip measuring device was used for strength measurements, and the sit and reach flexibility test was used for flexibility measurements. The data obtained from the study were analyzed using SPSS (Statistical Package for Social Sciences) for Windows 25.0. Descriptive statistical methods (number, percentage, mean, and standard deviation) were used in the evaluation of the data. The paired t-test, which is one of the parametric tests, was applied for the normally distributed parameters. According to the results of statistical analysis, a significant difference was found in the pre-test and post-test balance, flexibility and strength measurements of the participants $(\mathrm{p}<0.05)$. However, no statistically significant difference was found in the body mass index (BMI) values of the participants $(\mathrm{p}>0.05)$. In conclusion, it can be said that 6-week basic-level strength yoga exercises had a positive effect on balance, flexibility, and strength in soccer players. Furthermore, it may be suggested that yoga exercises to be applied by coaches before the season should be included in training programs considering that they will contribute to the motor development of soccer players.
\end{abstract}

Keywords Soccer, Yoga, Balance, Flexibility, Strength

\section{Introduction}

Soccer is a sports branch, which is watched with pleasure by people all over the world since it involves various combinations (fake, stopping, sudden movement, sprint, jump shot) [1]. The physical and physiological needs of soccer, which includes many combinations, are measured and tested through various exercises, and they are trained [2].

All physical, physiological, technical, and tactical needs are available in soccer. In addition to these needs, soccer players should also be prepared mentally and psychologically for the needs of soccer [3]. Before competitions, players try different methods in order to fulfill all of their physical and psychological characteristics at the highest level [4].

With this aspect, yoga is quite important in making soccer players ready for competitions and training psychologically and physiologically. Yoga is one of the oldest methods of rehabilitation to achieve physical strength and mental relaxation [5].

Yoga exercises that spread to the world through ancient India consist of a set of exercise movements designed to discipline the human body and mind [6]. Yoga exercises that have become popular by spreading to the world through ancient India have now begun to be used as assistive exercises in sports teams [7]. It is considered that yoga that physically affects flexibility and balance, as well as positive changes in the mind, has a positive effect on improving physical performance when it is practiced regularly [8].

Yoga is quite important to athletes because regular yoga practices affect emotional control, mental readiness, physical strength and balance, and making angles of movement with the widest angles [9, 8]. In some studies, it was observed that it had an effect on heart rate and strength and regulated blood pressure [10] It is suggested that yoga exercises should be done for the development of the motor properties present in the body and the maintenance of the technique because yoga is important 
not only for flexibility and strength development but also for technical and physical characteristics, and in combined sports such as soccer, athletes should reflect their highest physical characteristics in the field [11]. Yoga may help soccer players to achieve the desired level of performance and protect them from injuries [12]. Soccer players can improve their flexibility, strength, and endurance with yoga. They can increase their agility and levels of attention. In the literature, there are some studies carried out with yoga on soccer players.

Ajayaghosh et al. [13] (2018) indicated that soccer players who practiced yoga were focused on the game with more attention and had less risk of injury during the match compared to soccer players who did not practice yoga. In the study carried out by Lamani et al. (2016) on soccer players who practiced and did not practice yoga, a statistically significant difference was found in the selected motoric characteristics of soccer players, who practiced yoga for 6 weeks, at the end of 6 weeks. [11]

On the other hand, no study was found on yoga and soccer in our country. Therefore, the aim of this study was to investigate the effect of 6-week yoga exercises on balance, flexibility, and strength in soccer players.

\section{Materials and Methods}

Twenty-six soccer players competing in the Turkey Spor Toto 1st League, with a mean height of $180.81 \pm$ $6.87180 .81 \pm 6.87 \mathrm{~cm}$, a mean body weight of $75.77 \pm 9.08$ $\mathrm{kg}$, and a body mass index of $23.10 \pm 1.62$ voluntarily participated in this study. After the anthropometric measurements, standardized basic-level strength yoga exercises were applied to soccer players for 6 weeks, 4 times a week each for 30 minutes before training. Yoga exercises were determined in accordance with the asana yoga methods of Singh et al. [14]. The tests were applied to soccer players before and after 6-week yoga exercises. Attention was paid to the fact that soccer players had no injuries before and after the tests and that they had no problems in their levels of nutrition 24 hours before the tests. Immediately after the warm-up, the sit and reach flexibility test was used to determine flexibility capacity of soccer players, the isokinetic balance instrument was used to determine their balance levels, and the smart speed vertical jump test was used for the anaerobic strength measurement. The measurements of soccer players were performed in the facilities of soccer team sport measurement area.

\subsection{Anthropometric Measurements}

For the height measurements of soccer players, it was ensured that they wore only sports equipment in bare feet, the caliper sliding on the scale was adjusted to touch the players' head while they were standing upright with a Seca brand stadiometer, and the length was measured with
$1 \mathrm{~mm}$ precision. The measurements of soccer players' body weight were performed on the device by adjusting so that the soles of their feet were in full contact with the metal part of the scale while they were standing upright by ensuring that they wore sports equipment in bare feet.

\subsection{Sit and Reach Flexibility Test}

In this test, soccer players were asked to move the piece of wood on the sit and reach table forward with arms stretched. The participants were allowed to wear very fine things on their feet, and they were allowed to sit down on the bottom of the test material. In the full extension of two legs, the foot was ensured to be kept even against the end of the box. The participant tried to achieve the highest degree on the measuring ruler with arms stretched and palms down. Both hands made the movement to reach on the ruler in 4 times. They were asked to wait at least $1 \mathrm{sec}$ in the $4^{\text {th }}$ reach. The participants were given 1 trial, and the place of the board after the last reach was recorded in $\mathrm{cm}[15]$.

\subsection{Balance Test}

The dynamic balance test was performed while soccer players were standing with both legs on the Easytech dynamic balancing device. The soccer players on the dynamic balance device tried to stand within the center point by focusing their flowing balance levels on the computer screen. The Easytech balance board was set so that soccer players would move freely to the right or left. The visual feedback obtained from the computer screen was also used for the right position. In this test, the individual followed the reference position created by the movement of the circle on the computer screen by moving the platform and looked at the computer screen during the test. When the test period ended, the test was terminated automatically by the computer [16].

\subsection{Strength Test}

The hand grip dynamometer was fixed at the second handle for dominant hand position for measurement of hand grip strength. The participants were instructed to squeeze the handle of the dynamometer maximally and keep for 5 seconds. Average of the three measurements was recorded for the analysis purpose. [17]

\subsection{Yoga Protocol}

Soccer players performed standardized basic-level strength yoga exercises 4 times a week for 6 weeks. Yoga exercises of soccer players took place between 10.00 10.30 in the morning. In basic-level strength yoga exercises players made a total of 10 movements. The movements were made sequentially by repeating 2 times.

Standardized basic-level yoga exercises were applied as shown in table 1 Nayek et al. [5]. 
Table 1. The Basic-Level Strength Yoga Program Applied to Football Players

\begin{tabular}{|c|c|c|c|c|c|}
\hline \multirow[t]{2}{*}{ General } & \multirow[t]{2}{*}{ Training Program } & \multicolumn{4}{|c|}{ Basic-Level Strength Yoga Exercise } \\
\hline & & Tuesday & Wednesday & Thursday & Friday \\
\hline Total Time & 6 weeks & \multirow{4}{*}{$\begin{array}{c}\text { Vajrasana } \\
\text { Surya Namaskara } \\
\text { Bhujangasana } \\
\text { Parvatasana } \\
\text { Vrikshasana } \\
\text { Padasana Naukasana } \\
\text { Paschimattanasana } \\
\text { Makarasana } \\
\text { Savana }\end{array}$} & \multirow{4}{*}{$\begin{array}{c}\text { Vajrasana } \\
\text { Surya Namaskara } \\
\text { Bhujangasana } \\
\text { Parvatasana } \\
\text { Vrikshasana } \\
\text { Padasana } \\
\text { Naukasana } \\
\text { Paschimattanasana } \\
\text { Makarasana } \\
\text { Savana }\end{array}$} & \multirow{4}{*}{$\begin{array}{c}\text { Vajrasana } \\
\text { Surya Namaskara } \\
\text { Bhujangasana } \\
\text { Parvatasana } \\
\text { Vrikshasana } \\
\text { Padasana } \\
\text { Naukasana } \\
\text { Paschimattanasana } \\
\text { Makarasana } \\
\text { Savana } \\
\end{array}$} & \multirow{4}{*}{$\begin{array}{c}\text { Vajrasana } \\
\text { Surya Namaskara } \\
\text { Bhujangasana } \\
\text { Parvatasana } \\
\text { Vrikshasana } \\
\text { Padasana } \\
\text { Naukasana } \\
\text { Paschimattanasana } \\
\text { Makarasana } \\
\text { Savana } \\
\end{array}$} \\
\hline Weekly program & 4 days & & & & \\
\hline Number of Repeats & 2 repeats & & & & \\
\hline Hour & $10.00-10.30$ & & & & \\
\hline
\end{tabular}

Table 2. Descriptive statistics of the soccer players participating in the study

\begin{tabular}{ccccccc}
\hline & Minimum & $\begin{array}{c}\text { Pre-test } \\
\text { Maximum }\end{array}$ & Mean $\underline{ \pm}$ SD & Minimum & $\begin{array}{c}\text { Post-test } \\
\text { Maximum }\end{array}$ & Mean $\underline{\mathbf{S D}}$ \\
\hline Height & 169.00 & 193.00 & $180.81 \pm 6.87$ & 169 & 193.00 & $180.81 \pm 6.87$ \\
Weight & 59.00 & 90.00 & $75.77 \pm 9.08$ & 59.90 & 89.10 & $75.45 \pm 8.96$ \\
Balance & 8.30 & 18.30 & $13.01 \pm 2.81$ & 7.00 & 12.20 & $9.94 \pm 1.74$ \\
Flexibility & 12.00 & 44.00 & $32.98 \pm 8.50$ & 22.00 & 48.00 & $38.77 \pm 5.92$ \\
Body Fat Percentage & 7.00 & 13.00 & $10.63 \pm 1.61$ & 7.00 & 12.00 & $9.96 \pm 1.38$ \\
Arm Strength & 33.00 & 52.00 & $43.19 \pm 5.17$ & 35.00 & 53.00 & $46.69 \pm 4.49$ \\
BMI & 19.30 & 26.20 & $23.10 \pm 1.62$ & 18.90 & 25.70 & $23.00 \pm 1.60$ \\
\hline
\end{tabular}

\section{Results}

Twenty-six soccer players, competing in the Turkey Football Federation Spor Toto 1st League, constituted the sample of this study aimed at determining the effect of 6-week basic-level yoga exercises on balance, flexibility, and strength in soccer players. In the following weeks of the study, no injury was observed on players' body, and the study was completed with the same number of participants initiated. The descriptive statistics of the participating soccer players are presented in Table 2.

Descriptive statistics for both pre-test and post-test for the variables of height, weight, balance, flexibility, body fat percentage, arm strength, and BMI of the football players participating in the study are presented in Table 2. Accordingly, it appears that the height of the participants was at a minimum of $169 \mathrm{~cm}$, at a maximum of $193 \mathrm{~cm}$, and the mean height was $180.81 \pm 6.87 \mathrm{~cm}$.

When the participants were examined with respect to the weight variable, it was determined that it was at a minimum of $59 \mathrm{~kg}$ and a maximum of $90 \mathrm{~kg}$, and the mean body weight was $75.77 \pm 9.08 \mathrm{~kg}$ in the pre-test, and it was at a minimum of $59.90 \mathrm{~kg}$ and a maximum of 89.10 $\mathrm{kg}$, and the mean body weight was $75.45 \pm 8.96 \mathrm{~kg}$ in the post-test.

When the participants were examined with respect to the balance variable, it was determined that it was at a minimum of 8.30 and a maximum of 18.30 , and the mean balance was $13.01 \pm 2.81$ in the pre-test, and it was at a minimum of 7.00 and a maximum of 12.20 , and the mean balance was $9.94 \pm 1.74$ in the post-test.

When the participants were examined with respect to the flexibility variable, it was determined that it was at a minimum of 12.00 and a maximum of 44.00 , and the mean flexibility was $32.98 \pm 8.50$ in the pre-test, and it was at a minimum of 22.00 and a maximum of 48.00 , and the mean flexibility was $38.77 \pm 5.92$ in the post-test.

When the participants were examined with respect to the body fat percentage variable, it was determined that the minimum was 7.00 and the maximum was 13.00 and the mean body fat percentage was $10.63 \pm 1.61$ in the pre-test, and the minimum 7.00 and the maximum 12.00 , and the mean body fat percentage was $9.96 \pm 1.38$ in the post-test.

When the participants were examined with respect to the arm strength variable, it was determined that it was at a minimum of 33.00 and a maximum of 52.00 , and the mean arm strength was $43.19 \pm 5.17$ in the pre-test, and it was at a minimum of 35.00 and at a maximum of 53.00, and the mean arm strength was $46.69 \pm 4.49$ in the post-test.

When the participants were examined with respect to the BMI variable, it was determined that it was at a minimum of 19.30 and a maximum of 26.20 , and the mean BMI was $23.10 \pm 1.62$ in the pre-test, and it was at a minimum of 18.90 and a maximum of 25.70 , and the mean BMI was $23.00 \pm 1.60$ in the post-test. 
Table 3. Comparison of the Participants' Performance Measurement Results

\begin{tabular}{|c|c|c|c|c|c|}
\hline Variables & Group & $\mathrm{N}$ & Mean \pm SD & $\mathrm{t}$ & $\mathrm{p}$ \\
\hline \multirow{2}{*}{ Weight } & Pre-test & 26 & $75.77 \pm 9.08$ & \multirow{2}{*}{0.780} & \multirow{2}{*}{0.442} \\
\hline & Post-test & 26 & $75.45 \pm 8.96$ & & \\
\hline \multirow{2}{*}{ Balance } & Pre-test & 26 & $13.01 \pm 2.81$ & \multirow{2}{*}{7.398} & \multirow{2}{*}{$0.000^{*}$} \\
\hline & Post-test & 26 & $9.94 \pm 1.74$ & & \\
\hline \multirow{2}{*}{ Flexibility } & Pre-test & 26 & $32.98 \pm 8.50$ & \multirow{2}{*}{-6.258} & \multirow{2}{*}{$0.000 *$} \\
\hline & Post-test & 26 & $38.77 \pm 5.92$ & & \\
\hline \multirow{2}{*}{ Body fat percentage } & Pre-test & 26 & $10.63 \pm 1.61$ & \multirow{2}{*}{4.755} & \multirow{2}{*}{$0.000 *$} \\
\hline & Post-test & 26 & $9.96 \pm 1.38$ & & \\
\hline \multirow{2}{*}{ Arm strength } & Pre-test & 26 & $43.19 \pm 5.17$ & \multirow{2}{*}{-5.661} & \multirow{2}{*}{$0.000^{*}$} \\
\hline & Post-test & 26 & $46.69 \pm 4.49$ & & \\
\hline \multirow{2}{*}{ BMI } & Pre-test & 26 & $23.10 \pm 1.62$ & \multirow{2}{*}{0.754} & \multirow{2}{*}{0.458} \\
\hline & Post-test & 26 & $23.00 \pm 1.60$ & & \\
\hline
\end{tabular}

* A statistically significant difference at $\mathrm{p}<0.05$

The paired t-test was performed to determine whether there was a statistically significant difference between the pre-test and post-test weight, balance, flexibility, body fat percentage, arm strength, and BMI variables. Accordingly, it was found that there was no statistically significant difference between the pre-test and post-test with respect to the mean weight of the participants $(t=0.780, p>0.05)$.

It was determined that there was a statistically significant difference between the pre-test and post-test with respect to the mean balance of the participants $(t=7.398, p<0.05)$. Accordingly, it appeared that the mean balance of the participants in the pre-test was higher than the mean balance in the post-test.

It was determined that there was a statistically significant difference between the pre-test and post-test with respect to the mean flexibility of the participants $(\mathrm{t}=-6.258, \mathrm{p}<0.05)$. Accordingly, it appeared that the mean flexibility of the participants in the post-test was higher than the mean flexibility in the pre-test.

It was determined that there was a statistically significant difference between the pre-test and post-test with respect to the mean body fat percentage of the participants $(t=4.755, p<0.05)$. Accordingly, it appeared that the mean body fat percentage of the participants in the pre-test was higher than the mean body fat percentage in the post-test.

It was determined that there was a statistically significant difference between the pre-test and post-test with respect to the mean arm strength of the participants $(\mathrm{t}=-5.661, \mathrm{p}<0.05)$. Accordingly, it appeared that the mean arm strength of the participants in the post-test was higher than the mean arm strength in the pre-test.

It was determined that there was no statistically significant difference between the pre-test and post-test with respect to the mean BMI of the participants $(t=0.754$, $\mathrm{p}>0.05)$.

\section{Discussion}

Yoga is a type of art and exercise that is performed to strengthen the mind and body. Yoga exercises aimed at improving the characteristics of athletes ensure that the person is disciplined by increasing his/her physical capacity [18]. Yoga, which is quite important for athletes, may help athletes to prepare themselves mentally and physically for other matches by removing the pressure they feel during or before matches [19].

Yoga is considered to provide a high quality of life for people and athletes and therefore can also be included in training programs as a type of exercise that helps athletes' development levels. Yoga, which has become popular since the ancient Indian period and is used as an alternative development method in many sports branches in the world, has also begun to be practiced recently by sports instructors in our country. Therefore, in this study, the aim is to investigate the effect of 6-week basic-level yoga exercises on balance, flexibility, and strength in football players.

In their study (2018), Ajayaghosh et al. examined the effect of functional strength and yoga training on physical characteristics and found that yoga training had a positive effect on the development of strength in football players. [13] Singh et al. conducted in 2011, examined the effect of 6-week yoga exercises on agility and strength in athletes, and it was found that yoga had a statistically positive effect on strength [14]. In the study carried out by Prasad et al. in 2016 on yoga in secondary school students, it was observed that yoga exercises had a positive effect on physical fitness and strength development of 12-14 age group children. [18]. In (2018), Raj et al. examined the effects of selected yoga poses and aerobic exercises on strength and agility in cricket players, and it was found that the strength characteristics of the yoga group were improved significantly at the end of 6 weeks. [20]. Chilamur et al. In 2018, examined the effect of basic yoga 
exercises on strength in athletes, and it was observed that 6-week yoga exercises had positive effects on the strength development of athletes. [21] Chander (2018), examined the strength development of wrestlers after 3-month regular yoga exercises and found a statistically significant difference in the strength development of yoga wrestlers [22]. (2017)

In this study, a statistically significant difference of $(p<0.05)$ was found in the effect of 6 -week basic-level yoga exercises on the strength of football players, and the results of the study are in parallel with the results of other studies.

Silver et al. (2005) did not find a statistically significant difference in the effect of 6-week yoga on dynamic balance with 30 healthy men [23] In their study, Iftekher et al. (2017) examined the effect of yoga on balance and flexibility in athletes, and the effect of yoga on balance and flexibility was found to be statistically positive [8]. In (2010) study by Schmid et al. with old people, it was observed that 12-week yoga exercises contributed to balance by $4 \%$ and to flexibility by $34 \%$. [24]

In the study carried out by Jain et al. (2019) the effect of yoga poses on balance was examined, and it was statistically found that yoga had a positive effect on balance. [25] In study on Kabbadi players, Prashar (2019) found that 6-week yoga exercises positively improved flexibility in players. In their study on athletes [19], Hardeep et al. (2018) found that 21-day yoga training had a positive effect on flexibility [26]. In 8-week yoga studies on people with disabilities carried out by Sukumar (2017), it was observed that the balance and flexibility characteristics of individuals in the study improved. [27]. In (2017) in which the effect of yoga on flexibility in young athletes was examined, it was observed that yoga had an effect on flexibility in children aged 12-14 with a Bhavana yoga program. [28]

In the review study carried out by Adling et al. in (2017) on the benefits of yoga in professional athletes, the benefits of yoga with respect to flexibility and balance were revealed. [29]

In this study, it was statistically found that 6-week basic-level yoga exercises had positive effects on flexibility and balance in football players. When other literature studies related to yoga exercises are examined, it appears that there is a correlation of this study with them.

Vishnu et al. examined the effect of yoga practice on physiological parameters of Male Handball players and found a statistically difference in the shoulder strength and breath holding time and resting heart rate.[30] Mohod et al. (2019) found a statistical difference of soccer players breath holding and resting heart rate after asana training program [31] Thirumalaisamy (2017) found that 6 week Prayanama, Dhayana yoga exercises has effects on men players physiological parameters [32]

Soccer, Handball and Basketball all same kind sport need an anaerobic power that studies show that yoga could affect anaerobic power on soccer cause of branch needings.

In conclusion, it is considered that regular yoga exercises may help football players to achieve a higher performance level by contributing positively to motoric characteristics such as strength, balance, and flexibility in football players. Yoga exercise programs can be an alternative program for coaches so they can include them in training programs.

\section{REFERENCES}

[1] [1] Karabulak A., Kılınç F. The Effect of the Combined Training Applied to Male Football Players Aged 12-14 Years on Their Strength and Some Physiological Characteristics. Journal of Strategic Research in Social Science. (3):2: 116-130. 2017.

[2] Reilly T. An Ergonomics Model of the Soccer Training Process. Journal of Sport Sciences. (23):6 561-572. 2003.

[3] Eniseler N. Bilimin Işı̆̆ında Futbolda Sınırlı Alan Oyunlar1 [Limited Area Games in Football in the Light of Science]. Bassaray Matbaası. İzmir. 2018.

[4] Woody A. The Effects of Yoga Conditioning for Athletes on Cardiorespiratory Endurance. Cantaurus. 16: 28-31. 2008.

[5] Nayek B. Chatterjee K. Effects of 6 Weeks Yoga and Aerobic Exercise on Muscular Strength and Flexibility of Pre-Adolescence Students. International Journal of Yogi, Human Movement and Sport Science. 1(1): 12-16. 2016.

[6] Premkumar J. Mariayyah P. Effect of Selected Hathayogic Practices in Enhancing Kicking Ability in Soccer Playing. Journal of Exercise Science and Physiotherapy. 3(2): 168-170. 2007.

[7] Yadav S. Tadang M. Effect of 6 Weeks Yoga Asana on Basal Metabolic Rate of Novice Female Players. International Journal of Scientific and Research Publications. 3(7): 1-3. 2013.

[8] Iftekher N.S. Bakthiar N. Rahaman S. Effects on Yoga Flexibility and Balance. Asian Journal of Medical Biological Research. 3(2): 276-281. 2017.

[9] Kulkarni S.V. Effects of Selected Exercises in Yoga on Motor Fitness and Football Skills of Boys Aged 14 to 16 Years. Department Of Physical Education Science. Master Degree Thesis. Tibrewala University. 2017.

[10] Bhavanani AB, Madanmohan, Sanjay Z, Basavaraddi IV. Immediate Cardiovascular Effects Of Pranava Pranayama In Hypertensive Patients. Indian J Physiol Pharmacol. 56(3):273-278. 2012.

[11] Lamani C.G. Rathod D.S. Effects of Yoga Practice on Motor Ability Components Among Inter Collegiate Cricket and Football Players of BITS, Pilani K. K. Birla Goa Campus Deemed University Team. International Journal of Multidisciplinary Education and Research. 1(1):23-25. 2016. 
[12] Govindara N. Work capacity of elite school players practicing yoga in Pondicherry region" Yoga- Mimamsa, 34(2): 110-118. 2002.

[13] [13] Ajayagosh MV., Mahadevan V. Effect of Functional Strength Training and Vinyasa Flow Yoga on Selected Physical Variables Among Men Soccer Players. International Journal of Physiology, Nutrition and Physical Education. 3(2): 378-381. 2018.

[14] Singh A. Singh S. Gaurav V. Effects of 6 Weeks Yogasanas Training on Agility and Muscular Strength in Sportsmen. International Journal of Educational Research and Technology. 2(2): 72-74. 2011.

[15] Cerrahoğlu N., Günar B.B., Abanoz H. The Effects on Physical Fitness of 4 Month Physical Activity Program in Autistic Children. Social Sciences Studies Journal. Vol. 3 No. 11. 1578-1586. 2017.

[16] Erkmen N. Suveren S. Göktepe A.S. Yazıcıoğlu K. A Comparison of Balance Performance of Athletes in Different Branches. Spormetre Beden Eğitimi ve Spor Bilimleri Dergisi. 5(3): 115-122. 2007.

[17] Zafar H., Alghadir A., Anwer S. Effects of Head-Neck Position on the Hand Grip Strength in Healthy Young Adults: A Cross-Sectional Study. Biomed Research İnternational. 1-5. 2018.

[18] Prasad S.D. Samanta D. Effect of 6 Weeks Asana and Pranyama Yoga 2016.

[19] PrasahV. Effect of Yogic Exercises on Flexibility and Agility of the Kabbadi and Kho-Kho Players. International Journal of Yoga, Physiotherapy and Physical Education. 4(3): 25-27. 2019.

[20] Raj T.S. Sudheer G. Effect of Specific Yoga and Aerobic Exercises on Selected Motor Abilities Among Cricket Players. International Journal of Yoga, Physiotherapy and Physical Education. 3(1):57-60. 2018.

[21] Chilamur D.C. Jyoti D.M. Effects of Yoganas Training on Strength in Sportsmen's. International Journal of Yoga, Physiotherapy and Physical Education. 3(1): 214-216. 2018.

[22] Chander S. Effect of Yoga Asana on Physical Fitness of Young Wrestlers. International Journal of Yoga, Physiotherapy and Physical Education. 3(2): 318-319.
2018.

[23] Silver T., Mokha B.M. Effects of 6 Weeks Yoga Training on Selected Measures of Static and Dynamic Balance. ISBS. 679-683. 2005.

[24] Schmid A. Puymbroeck V.M. Koceja M.D. Effect of a 12-Week Yoga Intervention on Fear of Falling and Balance in Older Adults: A Pilot Study. Arch Phys Med Rehabil. 91: 576-583. 2010.

[25] Jain M. Yoga Poses to Balance Panch Maha Bhuta \& to Cure Diseases. International Journal of Yoga, Physiothearpy and Physical Education. (4):3. 61-63. 2019.

[26] Hardeep. Effect of Yogic Training Program on Agility of B.P. ED Students. International Journal of Yoga, Physiotherapy and Physical Education. 3(2): 188-189. 2018.

[27] Sukumar B. Effect of 8 Weeks Yoga Training on Balance and Hand Eye Coordination of Individuals With Intellectual Disabilities. International Journal of Yoga, Physiotherapy and Physical Education. 2(2): 38-41. 2017.

[28] Bhavana M. Efficacy of Yoga on Flexibility. International Journal of Yoga, Physiotherapy and Physical Education. 2(3): 45-49. 2017.

[29] Adling R. Bangar D. Yoga Effect on Sport Performance. International Journal of Yoga, Physiotherapy and Physical Education. 2(2): 29-32. 2017.

[30] Raj V. Effect of Yogic Practices on Physical and Physiological Parameters of İnter-Collegiate Male Handball Players. International Journal of Yoga, Physiotherapy and Physical Education. 2(5): 5-7. 2018

[31] Mohod J.W. Asanare D.M. Effect of Yoga Asana Training Program on Selected Motor Ability, Physiological and Psychological Variables of Football Players of Nasik District. International Journal of Physiology, Nutrition and Physical Education. 4(1): 163-165. 2019.

[32] Thirumalaisamy R. Effects of Yorgic Practices, Physical Exercises and Combination of Yogic Practices and Physical Exercises on Selected Motor Ability Components, Physiological and Psychological Variables of University Men Players. Shanlax International Journal of Arts, Science and Humanities. 5(1): 122-125. 2017. 